\title{
THE JOINT TERRASAR-X / TANDEM-X MISSION PLANNING SYSTEM
}

\author{
F. Mrowka, M. P. Geyer, C. Lenzen, A. Spörl, T. Göttfert, E. Maurer, M. Wickler, B. Schättler \\ German Aerospace Center (DLR), Oberpfaffenhofen, Germany
}

\begin{abstract}
This paper recalls the essential system requirements and elements for the joint TerraSAR-X / TanDEM-X mission planning system. Its commissioning approach, tests and results are described in detail.
\end{abstract}

\section{Index Terms- TanDEM-X, Mission Planning, Formation Flight}

\section{INTRODUCTION}

The successful launch of the TDX-1 satellite at June 21, 2010, marked the beginning of the challenging TerraSAR$X$ add-on for Digital Elevation Measurement mission TanDEM-X. Its primary mission goal is the consistent generation of a world-wide global digital elevation model with high accuracy [1]. The satellites TSX-1 and TDX-1 are therefore flown in close formation to build a single-pass space-borne radar interferometer. The nominal TSX-1 /TDX-1 life-time overlap of three years is used to cover the complete Earth twice under different baseline configurations. Both satellites are used in parallel for the bistatic DEM data acquisitions. To counterbalance the interferometric usage of TSX-1, the on-going operational TerraSAR-X mission data have to be acquired by both satellites TSX-1 and TDX-1.

The TanDEM-X mission required a major expansion of DLR's TerraSAR-X ground segment [2], [3]. Specifically, a new mission planning system MPS-tsm-tdm being in charge of generating combined TerraSAR-X and TanDEM$\mathrm{X}$ mission timelines for both satellites TSX-1 and TDX-1 had to be built up and to replace the TerraSAR-X single satellite only MPS-tsx planning system [4]. Specifically the combination of the two active and independent TSX-1 and TDX-1 instruments flying in spitting distance, asked for the implementation of specific precaution measures to prevent e.g. a mutual illumination. Furthermore, TanDEM-X data taking has to use both instruments in a synchronized manner, e.g. w.r.t. the data take start times. Adequate resource models, e.g. for downlink and power, have to be used in order to exploit the imaging capabilities to a maximum extent.

\section{TANDEM-X MISSION PLANNING CHALLENGES}

The challenges to be met by the joint TerraSAR$\mathrm{X} /$ TanDEM-X mission planning system are manifold and the resulting extensions are described in detail in [5]. Here, we briefly introduce the most prominent ones.

\subsection{Two Missions and Two Satellites}

It is a characteristic of the TerraSAR-X mission, that end users order an individual imaging of their region of interest, whereas the TanDEM-X mission has to systematically acquire a global data set. Both missions have to share the same set of two satellites which are moreover flown in spitting distance to each other. The transition from the "one mission one satellite" (TerraSAR-X TSX-1) to the "two missions two satellites" (TerraSAR-X/TanDEM-X TSX-1/TDX-1) certainly more than quadruplicated the mission planning complexity.

For TanDEM-X data takes, it is up to mission planning to decide which satellite is used as the active one, i.e. for both transmitting and receiving, and which satellite is consequently used in receive-only mode. TerraSAR-X data have to be assigned to either one of the two satellites. This load distribution has to assure a balance between TerraSAR-X and TanDEM-X usage while exploiting the given system resources to their best and obeying specific precaution measures.

\subsection{Mutual Illumination Risks}

One of the major challenges to be mastered by the mission operations segment is to ensure that the two satellites do not illuminate each other, as this could result in an irreparable damage. A detailed description is found in [6]. The involved mission planning aspects are described briefly.

Based on the so called transmit exclusion window information, which is provided by flight dynamics, the selection of the active transmitting satellite has no degree of freedom in certain time periods. As this information can be calculated for the next 18 hours only within an acceptable accuracy margin, mission planning has to ensure that the most recent transmit exclusion window information is used. 
Another counter measure to minimize the mutual illumination risk to a maximum extent is the insertion of so called SyncWarnings. These are isochronal instrument activities on both satellites with a bidirectional exchange of sync pulses via one of six sync horns. In case one of the satellites get's no feed back from the other (i.e. the state/position of the other satellite is unknown), its instrument is switched to receive-only mode.

\subsection{TerraSAR-X Priority Concept and TanDEM-X}

The TerraSAR-X mission uses a priority concept to manage conflicting user acquisition requests which furthermore allows out-balancing the commercial and science usage. This priority concept is applied in the TanDEM-X mission as well, but needed an extension w.r.t. its technical implementation. Since a data take contributing to the final global DEM has to be acquired under predefined effective baseline conditions, its execution has to be assured whilst the two satellites show this geometrical condition. Therefore, a preferred acquisition time window during which these conditions are met at its best is defined and a certain priority assigned. Since this preferred window is rather short, a second and larger acquisition window is laid around it and thus more flexibility concerning the acquisition opportunity is gained. The acquisition request gets lowest (background) priority at the larger time window start and then its pre-defined priority at the start of the preferred window, during which it is usually executed. If not, the same priority is maintained until the end of the larger acquisition window approaches. Then the priority is set to a high value to maximize its execution probability. As this is a crucial mechanism, a monitoring process has been established on mission planning site and appropriate information called DEMFlexibility is provided for the science and the commercial coordinators.

\subsection{X-Band Downlink and On-Board Memory Modeling}

In comparison to the TerraSAR-X mission based on the TSX-1 satellite alone, the downlink capacity and thus the number of downlinks per day is considerably enlarged through the TanDEM-X ground station network [7]. Since TDX-1 and TSX-1 share the same X-Band downlink frequency, mission planning has to ensure that their downlinks are not performed in parallel, but still has to make an optimum use of each contact by downlinking data from both satellites. As an answer to the limited number of $\mathrm{X}$-band transmitter on-off-cycles over the satellite life time, a so called hot-standby mode reducing the overall number of switches was implemented.

Despite the most similar design of TDX-1 with TSX-1, a major difference from the mission planning perspective is the solid state mass memory size which is doubled on TDX-1. To ensure the utilization of this additional memory on one hand and a balanced utilization of the two satellites on the other hand a so called downlink delay on TDX-1 was introduced. Simply speaking the TSX-1 memory is freed right away in the first possible downlink contact after the acquisition whereas the TDX-1 one is down linked only after a specific fill level has been reached. This is a most effective mechanism for the global DEM acquisition and also useful for TerraSAR-X background data acquisition.

\subsection{Power and Thermal Constraints}

For TerraSAR-X on TSX-1, the application of a simple power and thermal model based on a sliding window accumulating the acquisition time over one orbit was sufficient. A more elaborated thermal model based on 15 different sliding windows had to be introduced for TanDEM-X to satisfy its high orbit usage need. To model the power a completely new constraint set was incorporated in the scheduling process, including the power consumption of the SAR instrument in active and in passive role, X-Band transmitter in transmit and hotstandby mode, the battery input coming from the solar panels including earth and moon eclipse times or resulting from the satellites attitude, etc.

A number of further and not less important changes are e.g. additional inter-satellite constraints, short notice planning provision for both satellites, a long term timeline provision and the data take splitting for global DEM acquisitions. They are described in detail in [5].

\section{FROM THE TERRASAR-X ONLY TO THE COMBINED TERRASAR-X/TANDEM-X MISSION PLANNING SYSTEM}

\subsection{Commissioning and Operational Release Rationale}

The basic verification, validation and commissioning principles as already applied for the setup of the TerraSAR$\mathrm{X}$ ground segment [2] were followed for the TanDEM-X ground segment as well: A thorough pre-launch validation not only of the stand-alone mission planning system itself, but also of the ground segment in the frame of end-to-end system validation tests was performed. During the commissioning phase, its operational qualification in parallel to the comprehensive technical system calibration and verification was performed.

However, the roll-out of the new combined TerraSAR$\mathrm{X} /$ TanDEM-X mission planning system MPS-tsm-tdm posed a specific challenge to be mastered: It had to replace the operational single TerraSAR-X satellite planning system MPS-tsx in such a way, that the TerraSAR-X mission operation could be continued with the same reliability and robustness as reached over the last years. The transition had to be accomplished within a short maintenance period of a few days.

The commissioning and operational release of MPS-tsm$t d m$ was done in well-defined stages in line with the 
commissioning of the joint TerraSAR-X/TanDEM-X ground segment [8]. During the first part of the commissioning phase, as long as TSX-1 and TDX-1 were flying in a $20 \mathrm{~km}$ along-track distance, the new MPS-tsm$t d m$ was used for the TDX-1 timeline generation in support of the TDX-1 commissioning whilst the TerraSAR-X TSX1 only planning system MPS-tsx was still in operational use for the TerraSAR-X mission.

\subsection{Prelaunch Testing}

An extensive test program was conducted prior to the TDX-1 launch. Mission planning system internal tests with focus on interfaces and functionality were passed first. Valuable feed-back was gained by loading the generated timelines into the TDX-1 spacecraft simulator. Problematic TerraSAR-X test conditions were stimulated and the obtained results compared to those obtained from the operational MPS-tsx. On ground segment level, end-to-end workflows tests were performed comprising the ordering and planning of both TerraSAR-X and TanDEM-X data takes, the generation of the combined timelines for both satellites TSX-1 and TDX-1, and their execution using the on-ground integrated TDX-1 satellite.

\subsection{Drift and Pursuit Monostatic Commissioning Phase} Right after successful LEOP completion, the new MPS$t s m-t d m$ was put in charge to generate the timelines for the TDX-1 satellite, i.e. to plan all TDX-1 SAR instrument and downlink activities, while the MPS-tsx continued its operational service for the TSX-1 satellite.

All external TerraSAR-X user orders were routed by the production control of the Payload Ground Segment PGS into MPS-tsx for execution at the TSX-1 satellite. The system internal commissioning users were allowed to specify in their orders either the operational MPS-tsx or the new MPS-tsm-tdm as planning instance. In case of MPS$t s m-t d m$, they could explicitly specify the satellite of their choice (usually TDX-1) or leave that selection to the planning process itself. Again the appropriate routing was done by the PGS production control. The MPS-tsx generated timelines were uploaded to and executed by TSX-1. The MPS-tsm-tdm always generated the combined TerraSAR-X/TanDEM-X timelines for both satellites TSX1 and TDX-1. The one for TDX-1 was uploaded to and executed by the TDX-1, the "fictive" one for TSX-1 was mostly used for offline inspection and in specific cases checks with the spacecraft simulator were performed.

All TanDEM-X (pursuit monostatic) orders were generated within the Instrument Operations and Calibration segment (responsible for the long-term TanDEM-X data acquisition) and routed via PGS into MPS-tsm-tdm for further planning. The acquisition order for the corresponding TSX-1 channel had to be realized via an internal TerraSAR-X system ordering specifying the same data taking conditions as in the TanDEM-X TSX-1 channel. Thus it was possible to even realize TanDEM-X data takes in pursuit monostatic configuration.

In the MPS-tsx was introduced only a specific identifier, commanded with the datatake replay, to ensure the proper routing on ground for the TerraSAR-X data to the TerraSAR-X processing chain and the TanDEM-X data to the TanDEM-X chain.

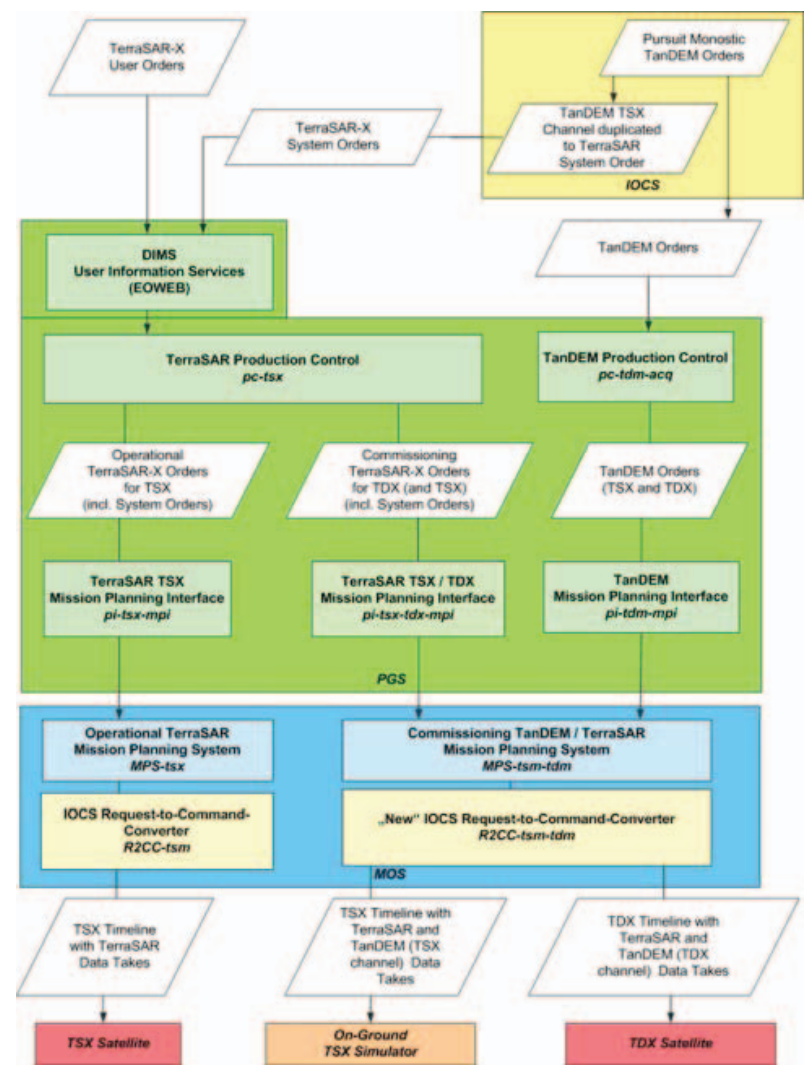

Fig. 1: Ground Segment Ordering and Planning Setup during Pursuit Monostatic Commissioning Phase.

Thus the MPS-tsm-tdm was thoroughly qualified during the first three months after launch and the replacement of the MPS-tsx was successfully performed beginning of October. This was a necessary prerequisite for the operation of the two satellites in their close formation, specifically for the bistatic instrument operation.

\subsection{Bistatic Commissioning Phase}

The close formation with its zero mean along-track separation was successfully adjusted by flight dynamics mid of October and the necessary precaution measures (exclusion zones and sync warning data takes) to avoid a mutual illumination of the two satellites were activated inside MPS-tsm-tdm. The first two generated timelines contained bistatic TanDEM-X data takes only, in the following days TerraSAR-X mission data taking by both satellites was phased in. In only a few days, the check-out of MPS-tsm-tdm for the generation of the mixed 
TerraSAR-X/TanDEM-X timelines for both satellites TSX1 and TDX-1 was mastered, the bistatic commissioning phase could begin. The TerraSAR-X mission is served by the two satellites TSX-1 and TDX-1 since then.

As the last qualification before starting the routine operations, an end-to-end load test was conducted for the whole ground segment in order to demonstrate that all subsystems, including mission planning, can handle the high throughput of the TanDEM-X mission without affecting the on-going TerraSAR-X.

\subsection{Routine Operations Phase}

The routine bistatic data acquisition phase was started at December 12, 2010. One day later the mission planning system was switched into its automated and unattended operational mode generating two command timelines per day since then.

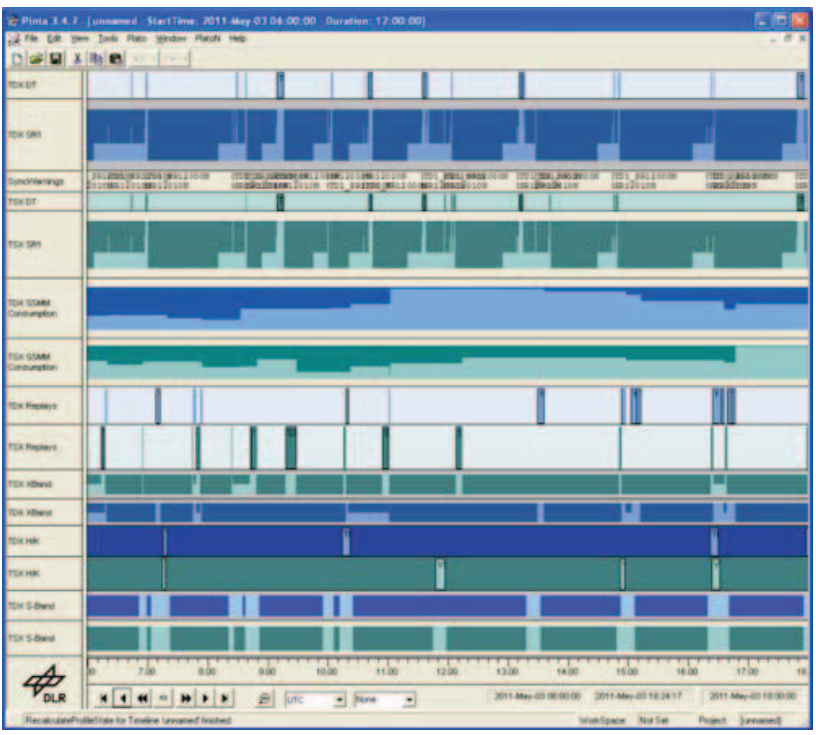

Fig. 2: A $12 \mathrm{~h}$ snap-shot of a command timeline. In this time frame were commanded:

- 24 replays (13 TSX-1 and 11 TDX-1) in 17 different downlink contacts to 6 different ground stations.

- 42 acquisitions (17 on TSX-1 and 25 on TDX-1) comprising 11 TanDEM-X pairs

- 15 Sync-Warnings

\section{ACKNOWLEDGMENT}

We thank the colleagues from the various teams of the ground, space and commercial service segment for their most valuable feed-back during the design, integration and validation testing of the mission planning system.

\section{REFERENCES}

[1] G. Krieger, A. Moreira, H. Fiedler, I. Haynsek, M. Werner, M. Younis, and M. Zink, "TanDEM-X: A Satellite Formation For High-Resolution SAR Interferometry", IEEE Transactions on Geoscience and Remote Sensing, Vol. 45, Number 11, pp. 3317 3341, November 2007.

[2] S. Buckreuss and B. Schättler, "The TerraSAR-X Ground Segment", IEEE Transactions on Geoscience and Remote Sensing, Vol. 48, Number 2, pp. 623 - 632, February 2010.

[3] B. Schättler, R. Kahle, U. Steinbrecher, R. Metzig, W.Balzer, and M. Zink, "Extending the TerraSAR-X Ground Segment for TanDEM-X", 8th European Conference on Synthetic Aperture Radar, Aachen, Germany, 7 - 10 June 2010, Electronic Proceedings

[4] E. Maurer, F. Mrowka, A. Braun, M.P. Geyer, C. Lenzen, Y. Wasser, and M. Wickler, "TerraSAR-X Mission Planning System: Automated Command Generation for Spacecraft Operations", IEEE Transactions on Geoscience and Remote Sensing, Vol. 48, Number 2, pp. 642 - 648, February 2010.

[5] M. P. Geyer, F. Mrowka, and C. Lenzen, "TerraSAR$\mathrm{X} /$ TanDEM-X Mission Planning - Handling Satellites in Close Formation", SpaceOps 2010 Book: 'Space Operations: Exploration, Scientific Utilization \& Technology Development', to be published Summer 2011.

[6] H. Hofmann and E. Maurer, "TanDEM-X Formation Flight Operation", 4th International Conference on Spacecraft Formation Flying Missions \& Technologies, Montreal, Canada, May $18-20,2011$

[7] R. Metzig, E. Dietrich, R. Reissig, M. Schwinger, F. Riffel, B. Schättler, "The TanDEM-X Ground Station Network", International Geoscience and Remote Sensing Symposium IGARSS 2011, Vancouver, Canada, July 24 - 29, 2011

[8] B. Schättler, R. Kahle, R. Metzig, U. Steinbrecher, M. Zink, "The Joint TerraSAR-X/TanDEM-X Ground Segment", International Geoscience and Remote Sensing Symposium IGARSS 2011, Vancouver, Canada, July 24 - 29, 2011

The TanDEM-X project is partly funded by the German Federal Ministry

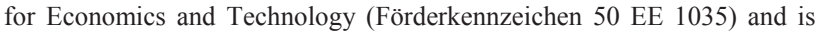
realized in a public-private partnership by DLR e.V. and Astrium EADS. 